\title{
La actividad documental en el ámbito periodístico: análisis comparativo y perspectivas
}

\author{
Yolanda Martín González \\ Departamento de Biblioteconomía y Documentación \\ Universidad de Salamanca (España) \\ María F. Sánchez Hernández \\ Facultad de Biblioteconomía y Documentación \\ Universidad de Extremadura (España)
}

\subsection{Resumen}

Se estudian las diferencias en las características, condiciones y responsables de las tareas documentales en los medios de comunicación impresa nacionales y locales, y se examina el proceso de adopción de las nuevas tecnologías en ellos. Se han tomado como referencia, en el ámbito nacional, los diarios El País, ABC y El Mundo, y, en el local, dos periódicos de la provincia de Salamanca, La Gaceta Regional y El Adelanto.

Palabras clave: Centros de documentación. Prensa.

\subsection{Abstract}

The differences in the characteristics, conditions and people in charge of the documentary tasks in the Spanish national and local press are studied, and their process of adoption of the new technologies is examined. The national newspapers El País, ABC y El Mundo, and the local rotatives La Gaceta Regional y El Adelanto (Salamanca, Spain) have been taken as examples.

Keywords: Information and documentation centers. Press.

\section{Introducción}

Los medios de comunicación constituyen un ámbito donde las prácticas documentales son de obligado cumplimiento, puesto que, para el eficaz desarrollo de la labor periodística, resulta indispensable una buena gestión y localización de las fuentes de información. La introducción de las nuevas tecnologías en el campo de las empresas informativas ha traído como consecuencia la aplicación de novedosos sistemas informáticos en sus servicios de documentación. Este hecho ha provocado una mayor diferenciación en la gestión, tratamiento y recuperación de la información documental entre los medios de comunicación nacionales y los medios de comunicación locales. Ante esta situación, resulta adecuado analizar

Scire. $10: 1$ (en.-jun. 2004) 237-241. 


\section{8}

Yolanda Martín Fernández y María F. Sánchez Hernández.

el estado - tanto general como particular - que presentan en la actualidad las unidades documentales sitas en medios de comunicación ante el reto de las nuevas tecnologías.

Dicho análisis implica las siguientes tareas: a) establecer una comparativa entre la situación en la que se encuentran en el momento presente los centros de documentación ubicados en medios de comunicación de ámbito nacional y local; b) examinar el proceso de adaptación de dichos centros al cambio tecnológico, especialmente en lo que se refiere al uso de sistemas informatizados de gestión y recuperación documental; c) poner de manifiesto la diferencia existente en la labor documental que se ejerce en ambos casos, determinada en gran medida por los medios técnicos con los que cuenta el diario; y d) evaluar el nivel de integración de los titulados en Documentación en el subsistema documental de los medios de comunicación.

Para conseguir nuestro objetivo estimamos oportuno visitar cada uno de los centros de documentación a estudiar, donde se mantuvo un encuentro con sus responsables. Ello permitió, por otro lado, conocer y comprobar personalmente el grado de efectividad de los servicios que ofrecen los sistemas de gestión automatizada en la recuperación de información. Una vez analizados pormenorizadamente los datos obtenidos, se estableció una comparativa en tres niveles: a) estado actual del servicio de documentación o archivo y consideración que recibe por parte de la plantilla del periódico; b) perfil del personal responsable del servicio - documentalista, periodista o informático-; y c) nivel de aplicación de las nuevas tecnologías en el servicio de documentación

\section{Consideraciones generales}

Los centros de documentación de medios de comunicación conforman un subsistema documental que intervine de forma fundamental en el funcionamiento de la empresa periodística (Ros, 1995). De este modo, puede decirse que su naturaleza responde especialmente a la labor que prestan al servicio de sus usuarios, esto es, los redactores. Estos servicios se encargan, entre otras cosas, de gestionar un tipo de información que, por lo general, presenta un importante valor económico. De ahí que incluso se comercialicen en muchos casos sus productos documentales. En la actualidad las tecnologías de la información y la comunicación (TICs) han transformado la práctica documental de los medios de comunicación, en los que la rapidez en la localización y recuperación de información constituye un requisito fundamental. Por otra parte, estos medios constituyen un ámbito de trabajo prácticamente nuevo para los titulados en Documentación, lo que nos parece interesante resaltar.

Scire. $10: 1$ (en.-jun. 2004) 237-241. 


\subsection{Los servicios de documentación de medios de comunicación nacionales}

\subsection{1. $A B C$}

El servicio de documentación del diario se establece desde el mismo momento de su fundación (1903). Desde entonces ha ido reuniendo un rico fondo textual y gráfico de creación propia en su mayoría, al que se añaden todas las colecciones de su editorial (Prensa Española), así como las colecciones microfilmadas de otras publicaciones. El proceso de automatización de su archivo se inicia en 1991. En la última década el rotativo ha puesto en marcha diferentes bases de datos que facilitan la recuperación de textos, documentos gráficos, etc., correspondientes a ediciones anteriores. Además, $A B C$ publica sus contenidos en CD-ROM y en los últimos años, ha apostado por aprovechar las posibilidades comunicativas que ofrece la Red proponiendo en su sitio web debates abiertos sobre distintos temas de interés. Para el desarrollo de las actividades de carácter documental, este diario cuenta con profesionales con formación en Documentación.

\subsubsection{El País}

El País inicia su proceso de informatización en 1983, concretamente con la creación de una base de datos referencial y de un índice que acompañase a la colección microfilmada del diario. Desde 1992 el diario cuenta con una conexión a otros servicios de información como Profi o Efedata. En 1994 se pone en marcha el sistema de recepción y almacenamiento digital de fotografías; y en 1995 comienza a funcionar su base de datos para documentos gráficos, permitiendo la catalogación, consulta y acceso a las fotografías originales. Este nuevo sistema ofrece prestaciones avanzadas como la recogida automática de varios registros: pie de foto, autor, fecha de entrada, catalogación, etc. Al igual que en el caso de $A B C$, su servicio de documentación está gestionado por profesionales de la Documentación.

\subsubsection{El Mundo}

Su servicio de documentación se crea con la fundación del diario en 1989. Desde el principio, además del archivo de documentos textuales, se fue constituyendo de forma paralela un archivo de imágenes. Los documentalistas que trabajan en el diario cuentan con una base de datos llamada ARCANO con la que llevan a cabo las tareas de selección documental, clasificación, catalogación, almacenamiento de páginas, textos, fotografías, gráficos y dibujos. Para la consulta de ediciones anteriores - conservadas todas ellas en formato digital-, se recurre al CD-ROM y al microfilm. Las distintas ediciones regionales que publica el diario se centralizan en el departamento de documentación en una única base de datos. Las tareas documentales son realizadas por profesionales con conocimientos en técnicas documentales. 


\subsection{Los servicios de documentación de medios de comunicación locales}

\subsubsection{El Adelanto de Salamanca}

Su hemeroteca, único servicio documental con el que cuenta este diario, se crea coincidiendo con su fundación en el año 1883. A diferencia de los que ocurre en los medios de comunicación nacionales, ésta consiste en una pequeña estancia amueblada con estanterías donde se ubican los archivos correspondientes únicamente a los tres últimos años. Estos archivos están ordenados por provincia, Salamanca, personas, tema y deportes. El resto se halla dispuesto en un almacén. Desde el mes de mayo de 2000, se ha puesto en marcha un sistema informatizado propio para la recuperación de material fotográfico en formato digital, que es gestionado por un informático. Dicho sistema permite localizar fotografías, bien por palabras utilizando los operadores lógicos, bien acotando las fechas. En la actualidad se está trabajando en la instalación de un sistema informático que permita la recuperación de documentos textuales. Por el momento, no existe ningún profesional, con o sin titulación en Documentación, que se ocupe del archivo - a excepción de los meses en los que realizan sus prácticas los alumnos de la Diplomatura de Biblioteconomía y Documentación-. Por lo general, cada redactor localiza personalmente el documento que le interesa.

\subsubsection{La Gaceta Regional de Salamanca}

Este diario comienza su andadura en 1920 pero su actual archivo se ha ido organizando desde 1984. Sus ejemplares están digitalizados desde 1920 a 1995 y desde 2001 a 2003. El resto está todavía en proceso de conversión. Las fotos digitales se organizan en tres archivos: biográfico, temático y geográfico. Para el desarrollo de la actividad documental cuentan con ARCANO, una aplicación que les permite realizar precisas búsquedas documentales Como en el caso anterior, cada periodista cuenta con acceso directo a Internet, lo que ha transformado en cierta manera la relación de los redactores con el servicio de documentación, aunque el tratamiento y gestión de la documentación son llevados a cabo por un titulado en Documentación. El diario comercializa alguno de sus productos documentales - anuarios y ejemplares del diario- en CD-ROM.

\section{Estudio comparativo}

Como se deduce claramente de lo expuesto con anterioridad, los servicios de documentación de medios de comunicación nacionales difieren notablemente de los servicios ubicados en medios de comunicación locales. Atendiendo a los niveles propuestos en las líneas introductorias, dichas diferencias pueden establecerse en tres estratos distintos. En primer lugar, respecto a la consideración que recibe la unidad documental, podemos afirmar que es aún notable la diferencia existente en la valoración que hacen los responsables de los medios de comunicación 
periodísticos nacionales y locales. Así, mientras que en los primeros el Centro de Documentación se reconoce como una ayuda inestimable para el desarrollo de la labor periodística, en los segundos esta situación puede variar ostensiblemente, dándose, por lo general, más valor a otro tipo de servicios. En segundo lugar, en lo relativo a la presencia del titulado en Documentación, ésta se halla mucho más reconocida en el ámbito de los medios de comunicación nacionales, e incluso podríamos afirmar que se encuentra prácticamente consolidada. En cambio, en los medios de comunicación locales encontramos que sólo en un determinado número de casos los responsables del servicio documental poseen algún tipo de titulación universitaria en Documentación. Por último, en lo que atañe a la aplicación de las nuevas tecnologías la situación dista mucho de poder compararse, siendo éste el factor que va a marcar en gran medida no sólo la diferencia en el grado de desarrollo de la actividad documental en la empresa periodística sino también la clave de su éxito.

Ante esta panorámica resulta evidente que la situación, especialmente de los centros de documentación de medios de comunicación local debe cambiar. La inserción de nuestros titulados en el ámbito documental puede considerarse como una garantía de que efectivamente el panorama puede llegar a transformarse. Para ello debe tenerse en cuenta que una correcta gestión del servicio de documentación se ha de basar en una inversión en medios tecnológicos que facilitan pero sobre todo agilizan la actividad documental; en la formación específica de personal especializado en las tareas de recopilación, selección, tratamiento, difusión, conservación y producción de la información; y en una rápida adaptación a las nuevas situaciones. En este sentido no podemos olvidar que el futuro de los medios de comunicación está cada vez más en los soportes virtuales en detrimento del formato papel.

\section{Referencias}

Arquesolo Vega, J. (1995). De la documentación informativa al periodismo de precisión. // Documentación de las Ciencias de la información. 18 (1995) 25-41.

Aumente, Jerome (1999). Bibliotecas, periodismo y Mass Media en la era digital de Internet: retos y transformaciones. // Documentación de las Ciencias de la Información 22 (1999) 61-74.

Ros García, J. (1995). El subsistema documental en el ámbito de la empresa informativa. // Documentación de las Ciencias de la información. 5:2 (1995) 185-193.

Sánchez Hernández, M.; Martín González, Y. (2002) Análisis de tres archivos de medios de comunicación ante el reto electrónico. // Jornadas Bibliotecarias de Andalucía (12 . 2002 Málaga). Los nuevos retos de los servicios bibliotecarios. 